\title{
Psychosocial Factors and Progression From Prehypertension to Hypertension or Coronary Heart Disease
}

\author{
Marty S. Player, MD \\ Dana E. King, MD, MS \\ Arch G. Mainous III, PbD \\ Mark E. Geesey, MS
}

Department of Family Medicine, Medical University of South Carolina, Charleston, SC

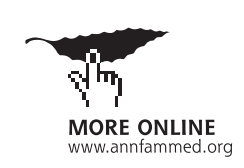

Conflicts of interest: none reported

\section{CORRESPONDING AUTHOR}

Marty Player, MD

Department of Family Medicine

Medical University of South Carolina

295 Calhoun St

Charleston, SC 29425

playerm@musc.edu

\begin{abstract}
PURPOSE This study explored the influence of trait anger and long-term psychological stress on progression to hypertension and incident coronary heart disease (CHD) in persons with prehypertension.
\end{abstract}

METHODS A secondary data analysis was performed using the Atherosclerosis Risk in Communities (ARIC) study, a cohort of men and women aged 45 to 64 years at enrollment. Participants with blood pressures in the prehypertension range at the second visit conducted between 1990 and 1992, free of heart disease or stroke, and observed through the end of the ARIC study (1996-1998) were included $(\mathrm{N}=2,334)$. The main outcomes were progression from prehypertension to hypertension and prehypertension to CHD or CHD death.

RESULTS After adjusting for various covariates, high levels of trait anger, compared with low/moderate levels (odds ratio [OR] 1.53; 95\% confidence interval [Cl], 1.052.24), were associated with progression from prehypertension to hypertension. After stratifying on sex, trait anger was predictive for men only (OR 1.71; 95\% Cl 1.04-2.83). In survival analysis, trait anger was associated with progression to CHD for men (hazard ratio [HR] 1.92; 95\% Cl, 1.07-3.54). Long-term psychological stress was also associated with risk of incident CHD (HR 1.68; 95\% Cl 1.18-2.40).

CONCLUSIONS High levels of trait anger in middle-aged prehypertensive men were associated with increased risk of progressing to hypertension and incident CHD. Long-term stress was also associated with increased risk of incident CHD in both men and women.

Ann Fam Med 2007;5:403-411. DOI: 10.1370/afm.738.

\section{INTRODUCTION}

$\mathrm{H}$ ypertension affects approximately 65 million Americans, ${ }^{1}$ and is associated with myocardial infarction, stroke, and disability in thousands of persons every year. ${ }^{2-4}$ According to Healthy People 2010, prevention of hypertension is one of the most critical public health needs of the coming decade. ${ }^{5}$ Also of great public health concern is coronary heart disease (CHD), which affects approximately 13 million persons in the United States and accounted for one-fifth of all deaths in the United States in $2002 .{ }^{6}$ Of all cardiovascular events, more than one-half are due to $\mathrm{CHD}$ in persons younger than 75 years. ${ }^{6,7}$

Hypertension is a well-established risk factor for CHD. Recently, however, a newer blood pressure designation of prehypertension has also been suggested as a condition of future risk. ${ }^{8,9}$ Prehypertension is defined as a systolic blood pressure of 120 to $139 \mathrm{~mm} \mathrm{Hg}$ or a diastolic blood pressure of 80 to $89 \mathrm{~mm} \mathrm{Hg} .{ }^{10}$ National estimates show that 27 million women and approximately 42 million men in the United States may have prehypertension. ${ }^{11,12}$ Evidence is growing that persons with prehypertension have higher cardiovascular risk factors ${ }^{13}$ and more cardiovascular events 
compared with those with normal blood pressure..$^{9,14,15}$ Further, patients with prehypertension are more likely to progress to frank hypertension. ${ }^{16}$

The role of various psychosocial factors in cardiovascular disease has been of interest for many years. In 1976 Medalie et al showed that anxiety and psychosocial problems related to family were associated with increased risk of developing angina in adult men. ${ }^{17}$ In terms of CHD, the Veteran's Administration's Normative Aging Study used various scales from the Minnesota Multiphasic Personality Inventory to show that anger was associated with coronary events ${ }^{18}$ and that type A behavior and depression were associated with incident CHD. ${ }^{19,20}$ A high trait anger level has also been shown to be associated with increased risk of stroke in persons younger than 60 years. ${ }^{21}$ Still further, anger and hostility have been shown to predict the development of atrial fibrillation in the Framingham Offspring Study. ${ }^{22}$

Symptoms of anxiety and depression in the National Health and Nutrition Examination Survey follow-up study ${ }^{23}$ and hostility and depressive symptoms in the Coronary Artery Risk Development in Young Adults were shown to be associated with incident hypertension in previously normotensive persons. ${ }^{24,25}$ A study in 2000 found that middle-aged adults with high anger levels and normal blood pressure had increased risk of $\mathrm{CHD}{ }^{26}$

None of these studies focused exclusively on persons with blood pressures in the prehypertensive range. The objective of this study was to investigate whether psychosocial factors are associated with progression from prehypertension to hypertension and to CHD or CHD mortality after adjustments for traditional risk factors. We analyzed data from a large population-based cohort study of atherosclerosis in adults. The study was institutional review board exempt.

\section{METHODS}

\section{Study Population}

The Atherosclerosis Risk in Communities Study (ARIC) is a prospective epidemiologic study of 15,792 men and women aged 45 to 64 years that began in 1987. It was designed to investigate the origin and progression of various atherosclerotic diseases. ${ }^{27}$ Recruitment for the study was by random probability sampling from population lists and area sampling in 4 communities across the United States, including Washington County, Maryland, suburban Minneapolis, Minnesota, Forsyth County, North Carolina, and Jackson, Mississippi. The full interview and examination methodology can be found on the ARIC Web site: http:// www.cscc.unc.edu/aric/pubuse/. The public use data set contains data from annual telephone interviews and 3 triennial visits (visits 2 through 4 ) that followed up on the cohort through the end of 1998.

Baseline measurements for this study were taken from the second clinical visit, which occurred from 1990 to 1992, because the psychosocial factors of interest were assessed at that visit. At this visit 14,348 participants $(92.9 \%$ of those from initial visit) were examined. Of those, we selected participants with blood pressures in the prehypertension range (120 to $139 \mathrm{~mm}$ $\mathrm{Hg}$ systolic or 80 to $89 \mathrm{~mm} \mathrm{Hg}$ diastolic). We excluded participants who had been told by a physician that they had high blood pressure, those who were taking antihypertensive medication, and those who had a measured systolic blood pressure of $140 \mathrm{~mm} \mathrm{Hg}$ and higher or diastolic blood pressure of $80 \mathrm{~mm} \mathrm{Hg}$ and higher. Additionally, we excluded participants with cardiovascular disease defined as having a history of myocardial infarction, stroke/transient ischemic attack, or cardiac revascularization procedures or electrocardiographic evidence of myocardial infarction. Thus, the initial cohort consisted of 2,334 participants from visit 2 who had prehypertension but were free of cardiovascular disease.

Participants were followed up through each of the remaining triennial clinical examinations, which included visit 3 (from 1993 to 1995) and visit 4 (from 1996 to1998); annual morbidity and mortality was determined by telephone follow-up. Follow-up ranged from 4 to 8 years.

\section{Development of Hypertension}

Participants were defined as having developed hypertension if, during visits 3 or 4 (3 to 6 years from visit 2 ), the measured systolic blood pressure was greater than $139 \mathrm{~mm} \mathrm{Hg}$ or diastolic blood pressure was greater than $89 \mathrm{~mm} \mathrm{Hg}$, if they reported having been told by a physician that they had high blood pressure, or if they were taking an antihypertensive medication.

\section{Development of CHD}

For the follow-up period through 1998, development of $\mathrm{CHD}$ or $\mathrm{CHD}$ death was defined as having an acute myocardial infarction, a silent myocardial infarction on an electrocardiogram reading, a cardiac revascularization procedure, or fatal CHD. Death certificates and hospital discharge summary data were used to verify hospital CHD events. Additionally, participants' next of kin and coroners' or medical examiners' reports were used to determine out-of-hospital causes and dates of death.

\section{Demographic Variables}

Demographic variables assessed as predictors include age, race, and sex. Patients were divided into 2 agegroups: those aged 48 to 57 years, and those aged 58 to 67 years. Race was defined as black and nonblack 
based on patient self-report. Although the ARIC data set has extensive race information, the public use limited-access data set is classified as black or nonblack.

\section{Cardiovascular Risk Variables}

Smoking status was defined as current or not current. Using body mass index (BMI) calculated as weight in kilograms divided by the square of the height in meters, we defined participants as nonobese (BMI of 30 or less) or obese (BMI more than 30). ${ }^{28}$ Those participants who stated at visit 2 they had been diagnosed with diabetes or were taking medications for diabetes were considered as having a history of diabetes. Patients with measured low-density lipoprotein (LDL) cholesterol levels of greater than $160 \mathrm{mg} / \mathrm{dL}$ were defined as having hyperlipidemia.

For assessment of physical activity, the ARIC data set includes information about the top 4 sports and leisuretime activities in which an individual participates. The hours per week and the months per year are reported for each activity, and these values then were used to calculate the average number of hours per week spent on that activity during the course of the year. We summed the average hours per week for these 4 activities. To this sum we added the average number of minutes per week of walking or riding a bicycle to and from work or shopping. Participants with a total of 150 minutes per week or more were classified as getting sufficient exercise. This standard is based on the longstanding recommendation of several groups, including the President's Fitness Coun$\mathrm{cil}^{29}$ and the American College of Sports Medicine. ${ }^{30}$

\section{Psychosocial Variables}

Three standardized self-administered psychosocial questionnaires were administered during the Health and Life Profile in the second visit of the ARIC study The first measure assessed each participant's satisfaction with life and his or her level of social support and social network. The Lubben Social Network scale assesses social networks among elderly people. ${ }^{31}$ The cohort was divided into tertiles ( 0 to 35,36 to 39,40 to 50). Long-term psychological stress (termed vital exhaustion) was assessed by the Maastricht Questionnaire. ${ }^{32}$ The cohort was divided into tertiles and classified as low, moderate, and high based upon their score ( 0 to 7,8 to 12 , greater than 12 ). Lastly, the 10 question Spielberger Trait Anger Scale was administered to assess levels of anger and hostility. ${ }^{33}$ Classifications of low (10 to 14$)$, moderate (15 to 21 ) and high (22 to 40 ) were based on previously published scores. ${ }^{21,26}$

\section{Statistical Analyses}

All analyses were performed using SUDAAN 9.0.1 statistical software. All continuous variables (age, BMI,
LDL cholesterol, hours of exercise, and psychosocial scores) were tested for normality. Because neither the variables, including age, BMI, LDL cholesterol, physical activity, nor the psychosocial scores were normally distributed, we chose to categorize the variables as indicated above for statistical analysis and interpretation.

Separate bivariate $\left(\chi^{2}\right)$ analyses were conducted examining which factors contributed to the development of hypertension or CHD in unadjusted analysis. In an effort to determine the best predictors of progression, we designated a priori that the categorical variables with a $P$ value of $<.2$ in bivariate analysis were to be included in the multivariable models. For progression to hypertension, odds ratios (OR) with 95\% confidence intervals $(\mathrm{CI})$ were calculated for the psychosocial variables using logistic regression modeling. Even though we investigated the development of disease, we used logistic regression rather than Cox regression and survival analysis, because time to event (development of hypertension) could not be precisely determined.

Cox proportional hazards regression was used to determine association between the psychosocial factors and incident CHD in participants with prehypertension. Detailed annual telephone follow-up and morbidity and mortality surveillance allowed for determination of time to event for this outcome. Crude probabilities of CHD event-free survival were determined by the Kaplan-Meier product-limit method.

Unadjusted associations between Maastricht score categories (long-term psychological stress) and anger categories were calculated using logistic regression for development of hypertension and Cox regression for development of CHD.

In the analyses, Maastricht scores and Spielberger anger scores were dichotomized into the highest tertile and the lowest 2 tertiles combined (high vs low/moderate), because in previous studies, high levels of the psychosocial variables have been the level commonly associated with various cardiovascular disease. ${ }^{21,22,26}$ The Lubben Social Network score was not included in the models as it was not associated with either outcome. We stratified by sex because previous studies using this anger scale have shown differences between men and women. ${ }^{22}$

To assess for confounding, we first performed $\chi^{2}$ analysis to determine which of the covariates were associated $(P<.05)$ with each of the psychosocial variables. Then we performed additional analyses including only these confounders in separate logistic and Cox regression models for the development of hypertension and incident CHD, respectively.

To test the sensitivity of our findings to the cutpoints used, we performed separate multivariable regression analyses, entering the covariate risk fac- 
tors as continuous rather than categorical variables, and found similar results (available in the online-only

Supplemental Table 1, found at http://www. annfammed.org/5/5/403/DC1.)

\section{RESULTS}

In bivariate analysis, age, sex, race, BMI, history of diabetes, LDL cholesterol, hours per week of exercise, Maastricht score, and Spielberger anger score had unadjusted $P$ values $<.2$ (Table 1 ) for progression to hypertension and were therefore included in the multivariable regression analysis for progression from prehypertension to hypertension. Current smoking status and Lubben Social Network scores were not significantly associated with the development of hypertension in unadjusted analysis $(P>.2)$ and were not included in the regression analysis.

Unadjusted associations for progression to hypertension by each psychosocial factor are displayed

\begin{tabular}{|c|c|c|c|c|c|}
\hline \multirow[b]{2}{*}{ Variable } & \multirow{2}{*}{$\begin{array}{l}\text { Population } \\
\text { No. (\%) }\end{array}$} & \multicolumn{2}{|c|}{$\begin{array}{l}\text { Development } \\
\text { of Hypertension }\end{array}$} & \multicolumn{2}{|c|}{$\begin{array}{l}\text { Development } \\
\text { of CHD/CHD Death }\end{array}$} \\
\hline & & $\%$ & $\chi^{2} P$ Value & $\%$ & $\chi^{2} P$ Value \\
\hline Age category & & & $<.001$ & & .014 \\
\hline $48-57$ y & $1,176(50.4)$ & 53.0 & & 9.6 & \\
\hline $58-67 y$ & $1,158(49.5)$ & 63.2 & & 12.9 & \\
\hline Sex & & & $<.001$ & & $<.001$ \\
\hline Male & $1,127(48.3)$ & 53.2 & & 17.0 & \\
\hline Female & $1,207(51.7)$ & 62.6 & & 5.8 & \\
\hline Race & & & $<.001$ & & .005 \\
\hline Nonblack & $1,863(79.8)$ & 56.0 & & 12.2 & \\
\hline Black & $471(20.2)$ & 66.3 & & 7.6 & \\
\hline Diabetes & & & .052 & & $<.001$ \\
\hline Yes & $117(5.0)$ & 67.3 & & 24.0 & \\
\hline No & $2,217(95.0)$ & 57.5 & & 10.5 & \\
\hline Low-density lipoprotein cholesterol & & & .110 & & .075 \\
\hline$\leq 160 \mathrm{mg} / \mathrm{dL}$ & $1,839(78.8)$ & 57.0 & & 10.5 & \\
\hline$>160 \mathrm{mg} / \mathrm{dL}$ & $495(21.2)$ & 61.4 & & 13.4 & \\
\hline Maastricht Questionnaire score & & & .045 & & .019 \\
\hline Low $(0-7)$ & $773(33.1)$ & 56.7 & & 10.1 & \\
\hline Moderate (8-12) & $756(32.4)$ & 55.1 & & 9.5 & \\
\hline High $(>12)$ & $805(34.5)$ & 61.6 & & 13.7 & \\
\hline Spielberger Trait Anger Scale score & & & .018 & & .011 \\
\hline Low (10-14) & $901(38.6)$ & 59.9 & & 9.8 & \\
\hline Moderate (15-21) & $1,272(54.5)$ & 55.6 & & 11.5 & \\
\hline High $(>21)$ & $161(6.9)$ & 66.7 & & 18.0 & \\
\hline$\geq 2.5$ & $1,351(57.9)$ & 56.8 & & 10.8 & \\
\hline Body mass index & & & .007 & & .362 \\
\hline$\leq 30$ & $1,671(71.6)$ & 56.3 & & 10.8 & \\
\hline$>30$ & $663(28.4)$ & 62.8 & & 12.2 & \\
\hline Exercise hours per week & & & .168 & & .484 \\
\hline$<2.5$ & $983(42.1)$ & 59.8 & & 11.8 & \\
\hline$\geq 2.5$ & $1,351(57.9)$ & 56.8 & & 10.8 & \\
\hline Current smoking status & & & .349 & & .021 \\
\hline Yes & $502(21.5)$ & 60.0 & & 14.0 & \\
\hline No & $1,832(78.5)$ & 57.5 & & 10.4 & \\
\hline Lubben Social Network score & & & .796 & & .220 \\
\hline Low (0-35) & $707(30.3)$ & 57.7 & & 12.5 & \\
\hline Moderate (36-39) & $728(31.2)$ & 57.6 & & 10.0 & \\
\hline High (>39) & $899(38.5)$ & 59.7 & & 8.8 & \\
\hline
\end{tabular}


in Table 2. In multivariable logistic regression analysis for progression from prehypertension to hypertension, high Spielberger trait anger scores compared with low/moderate scores (AOR 1.53; 95\% CI, 1.05-2.24) were associated with progression from prehypertension to hypertension (Table 3). Approximately $7 \%$ of those with prehypertension had a high trait anger score, but of those, almost $67 \%$ developed hypertension, with 1.5 times greater odds for developing hypertension than those with low/ moderate scores. Stratification by sex showed that high trait anger scores were associated with progression to hypertension in men only (AOR 1.71; 95\% CI, 1.04-2.83). Long-term stress as assessed by highest tertile Maastricht scores was not associated with progression from prehypertension to hypertension (AOR 1.06; 95\% CI, $0.87-1.30)$ and remained nonsignificant for both sexes after stratification.

Bivariate analysis results for prehypertensive participants developing CHD for each risk factor and psychosocial factor are displayed in Table 1. There was a significant difference between prehypertensive participants who developed CHD and those who did not for both long-term psychological stress and trait anger $(P<.05$ for both). In addition to these psychosocial factors, age category, sex, race, smoking status, diabetes, and LDL cholesterol category were significantly different between the 2 groups $(P<.2)$ and were therefore included in the Cox regression models as covariates. The Lubben Social Network scores were not associated with progression to $\mathrm{CHD}(P=.22)$ in unadjusted analysis and was therefore not included in the Cox regression model.

After adjusting for other risk factors (age, sex, race, smoking, and LDL cholesterol), there was an increased risk of incident CHD with high longterm psychological stress compared with low/moderate stress for both men and women (Table 4). High trait anger scores were associated with a $90 \%$

\begin{tabular}{|c|c|c|}
\hline Psychosocial Variable & $\begin{array}{l}\text { Progression to } \\
\text { Hypertension* } \\
\text { OR }(95 \% \mathrm{Cl})\end{array}$ & $\begin{array}{l}\text { Progression to } \\
\text { CHD/CHD Death } \\
\text { OR }(95 \% \mathrm{Cl})\end{array}$ \\
\hline \multicolumn{3}{|l|}{$\begin{array}{l}\text { Maastricht Questionnaire } \\
\text { score (long-term stress) }\end{array}$} \\
\hline Low/moderate & 1.00 & 1.00 \\
\hline High & $1.26(1.04-1.52)$ & $1.27(0.91-1.76)$ \\
\hline \multicolumn{3}{|l|}{$\begin{array}{l}\text { Spielberger Trait Anger } \\
\text { Scale score }\end{array}$} \\
\hline Low/moderate & 1.00 & 1.00 \\
\hline High & $1.49(1.03-2.14)$ & $2.14(1.31-3.49)$ \\
\hline \multicolumn{3}{|c|}{$\mathrm{CHD}=$ coronary heart disease; $\mathrm{OR}=$ odds ratio; $\mathrm{Cl}=$ confidence interval. } \\
\hline \multicolumn{3}{|c|}{$\begin{array}{l}\text { * Unadjusted simple logistic regressions. } \\
\text { † Unadjusted Cox survival analyses. }\end{array}$} \\
\hline
\end{tabular}

\section{Table 3. Logistic Regression Modeling for Likelihood of Developing Hypertension in a Population of Prehypertensive Middle-Aged Participants}

\begin{tabular}{|c|c|c|c|}
\hline Psychosocial Variable & $\begin{array}{l}\text { Total* } \\
\text { AOR }(95 \% \mathrm{CI})\end{array}$ & $\begin{array}{l}\text { Men }^{\dagger} \\
\text { AOR }(95 \% \mathrm{CI})\end{array}$ & $\begin{array}{l}\text { Women }^{\dagger} \\
\text { AOR }(95 \% \mathrm{CI})\end{array}$ \\
\hline \multicolumn{4}{|l|}{$\begin{array}{l}\text { Maastricht Questionnaire } \\
\text { score (long-term stress) }\end{array}$} \\
\hline Low/moderate & 1.00 & 1.00 & 1.00 \\
\hline High & $1.06(0.87-1.30)$ & $1.11(0.81-1.51)$ & $1.02(0.79-1.33)$ \\
\hline \multicolumn{4}{|l|}{$\begin{array}{l}\text { Spielberger Trait Anger } \\
\text { Scale score }\end{array}$} \\
\hline Low/moderate & 1.00 & 1.00 & 1.00 \\
\hline High & $1.53(1.05-2.24)$ & $1.71(1.04-2.83)$ & $1.34(0.76-2.36)$ \\
\hline \multicolumn{4}{|c|}{$\mathrm{AOR}=$ adjusted odds ratio; $\mathrm{Cl}=$ confidence interval. } \\
\hline \multicolumn{4}{|c|}{$\begin{array}{l}\text { *Adjusted for age category, race, sex, body mass index category, low-density lipoprotein cholesterol } \\
\text { category, diabetes, and exercise category. }\end{array}$} \\
\hline \multicolumn{4}{|c|}{$\begin{array}{l}\dagger \text { Adjusted for age category, race, body mass index category, low-density lipoprotein cholesterol cat- } \\
\text { egory, diabetes, and exercise category. }\end{array}$} \\
\hline
\end{tabular}

Table 4. Cox Regression Modeling for Likelihood of Experiencing a CHD Event or CHD Death in a Population of Prehypertensive Participants Initially Aged 48 to 67 Years

\begin{tabular}{|c|c|c|c|}
\hline Psychosocial Variable & $\begin{array}{c}\text { Total* } \\
\text { AHR }(95 \% \mathrm{CI})\end{array}$ & $\begin{array}{c}\text { Men }{ }^{\dagger} \\
\text { AHR }(95 \% \mathrm{CI})\end{array}$ & $\begin{array}{c}\text { Women }{ }^{\dagger} \\
\text { AHR }(95 \% \mathrm{CI})\end{array}$ \\
\hline \multicolumn{4}{|l|}{$\begin{array}{l}\text { Maastricht Questionnaire } \\
\text { score (long-term stress) }\end{array}$} \\
\hline Low/moderate & 1.00 & 1.00 & 1.00 \\
\hline High & $1.68(1.18-2.40)$ & $1.54(1.03-2.28)$ & $2.63(1.04-6.68)$ \\
\hline \multicolumn{4}{|l|}{$\begin{array}{l}\text { Spielberger Trait Anger } \\
\text { Scale score }\end{array}$} \\
\hline Low/moderate & 1.00 & 1.00 & 1.00 \\
\hline High & $1.71(0.99-2.93)$ & $1.92(1.07-3.45)$ & $0.95(0.20-4.51)$ \\
\hline
\end{tabular}


increase in the risk of progression to CHD in prehypertensive men but not significantly related to $\mathrm{CHD}$ in women. Crude Kaplan-Meier probability curves for long-term psychological stress and for trait anger by sex are displayed in Figures 1 through 3.

To assess for confounding, we first performed $\chi^{2}$ analysis to determine which of the covariates were associated $(P<.05)$ with each of the psychosocial variables. Then we performed additional analyses including only these confounders in separate logistic and Cox regression models for the development of hypertension and incident CHD, respectively. Results were similar to the findings from the initial models presented above (data not shown).

\section{DISCUSSION}

This study from a cohort of middle-aged adults in the US with prehypertension shows that among men with high trait anger scores, there is a modest association with progression to hypertension and CHD. The study also shows that long-term psychological stress is associated with development of combined CHD/CHD death for persons with prehypertension.

Trait anger as measured by the Spielberger Trait Anger Scale is a stable personality trait characterized by the frequency, intensity, and duration of anger. Those with high trait anger scores tend to experience anger more frequently with higher intensity and longer duration than those with low to moderate scores. ${ }^{33}$

Previous studies have shown a relationship between high levels of trait anger and coronary heart disease development in normortensive adults, ${ }^{26}$ as well as increased risk of incident stroke among a subset of patients. ${ }^{21}$ To our knowledge, no study has assessed its association with development of hypertension in a population with prehypertension.

The mechanism related to trait anger and progression to hypertension and CHD is unknown, but studies suggest that such biological mechanisms as sympathetic hyperactivity and arousal associated with anger and psychological stress may play a role in cardiovascular disease. ${ }^{34,35}$ Although one might consider that trait anger may be difficult to treat, a study by

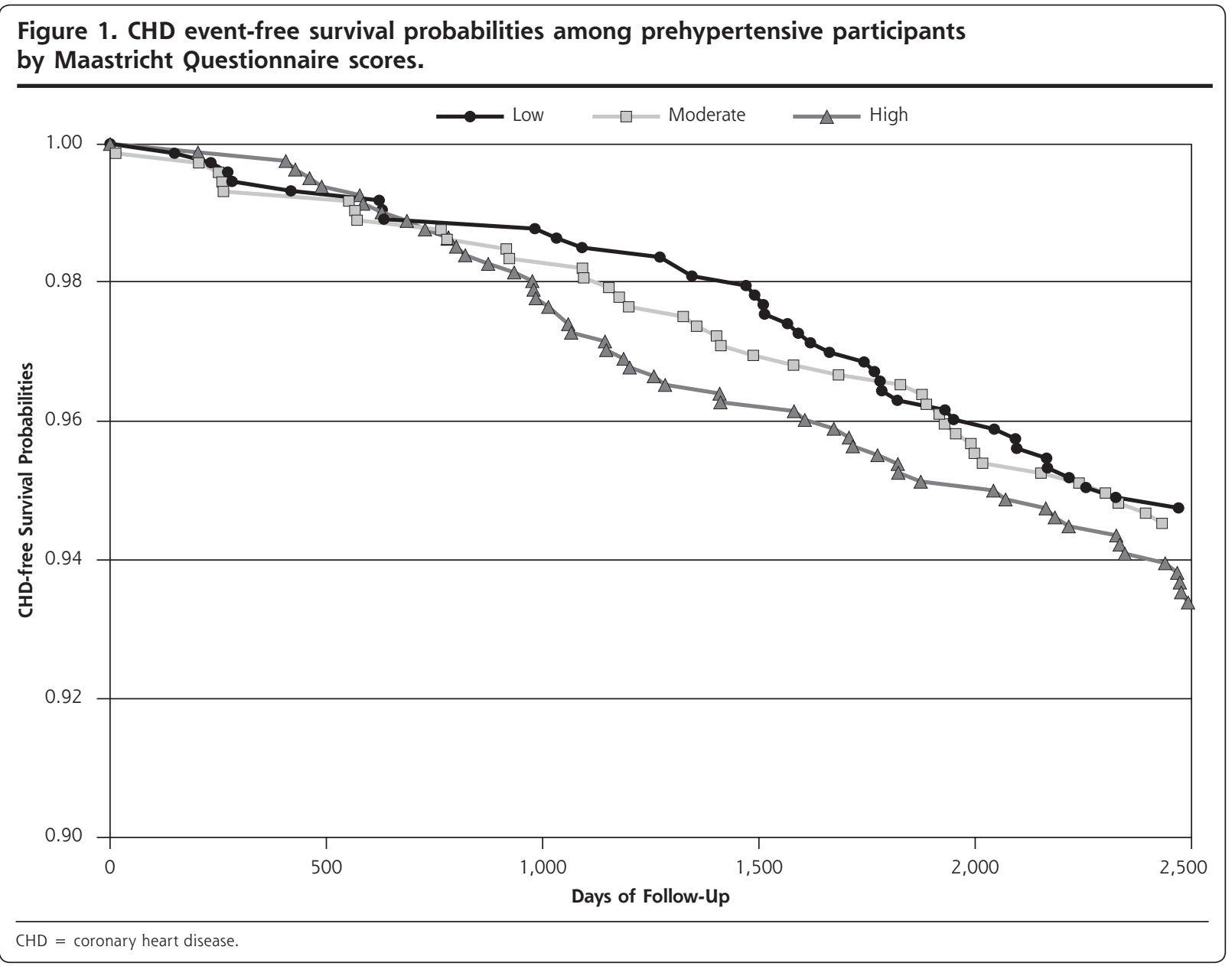


Figure 2. CHD event-free survival probabilities among prehypertensive men by Spielberger Trait Anger Scale scores.

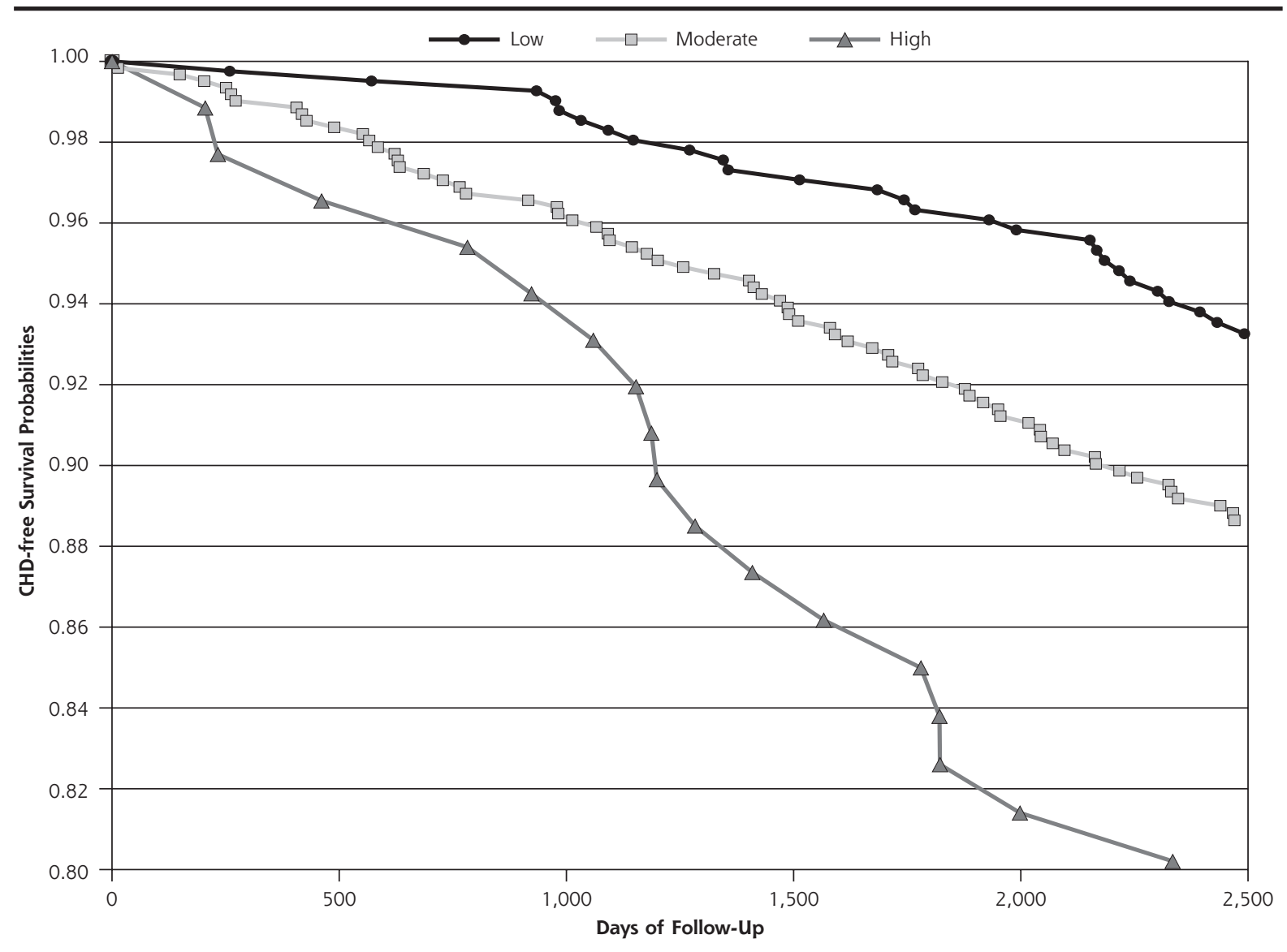

$\mathrm{CHD}=$ coronary heart disease

Figure 3. CHD event-free survival probabilities among prehypertensive women by Spielberger Trait Anger Scale scores.

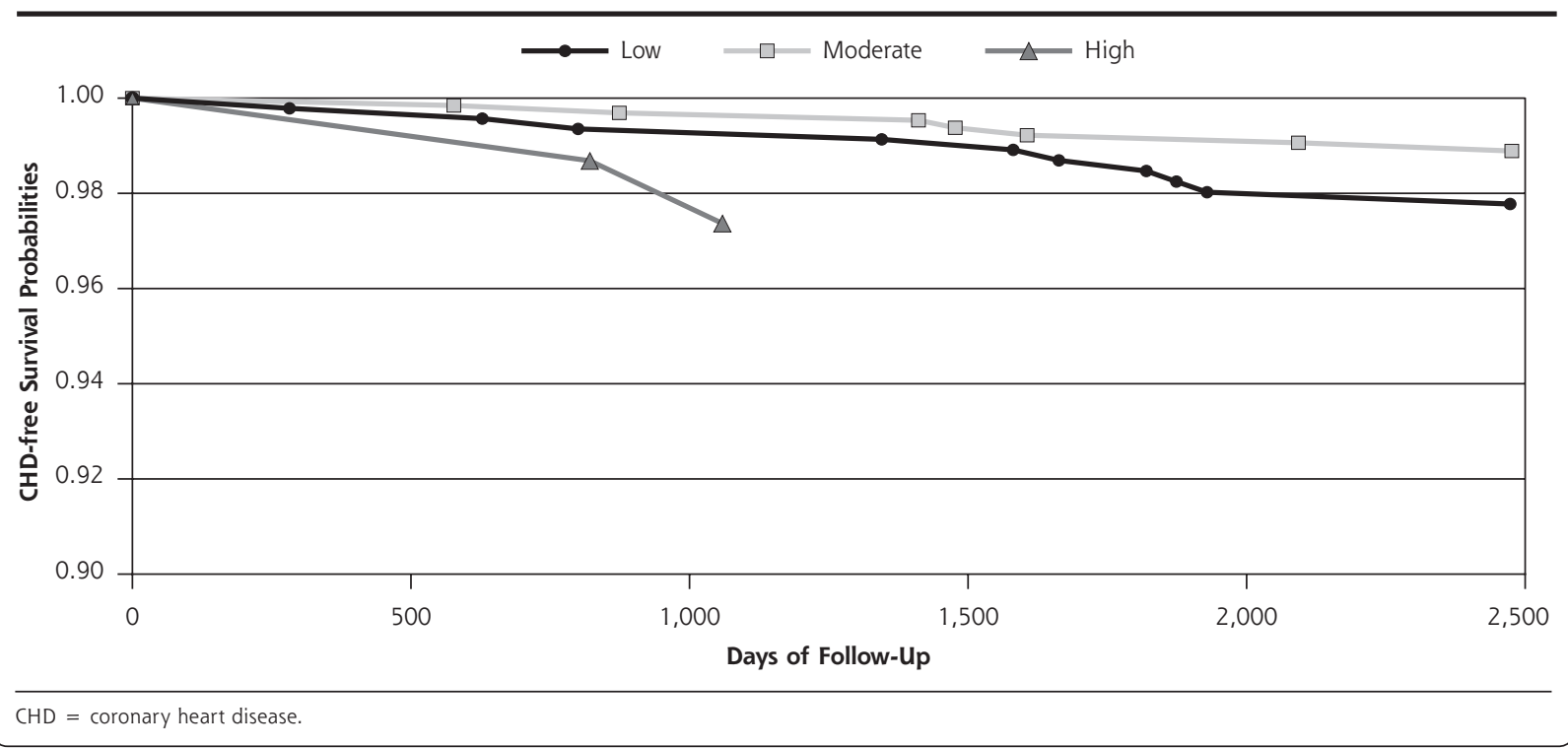


Blumenthal et al showed that a specified exercise program was successful in reducing both type A psychological scores and cardiovascular risk factors in middle-aged adults. ${ }^{36}$ Further studies may help determine whether treatment of anger by counseling, medication, or other means will have a beneficial effect on slowing progression from prehypertension to CHD.

Psychological stress as assessed by the Maastricht Questionnaire was initially designed to assess symptoms of fatigue and depression that precede myocardial infarction. Specifically, the questionnaire assesses feelings of fatigue, lack of energy, worsening irritability, and feelings of demoralization. Appels and Mulder found that the stress measure was associated with increased myocardial infarction risk as well as an association with nonfatal myocardial infarction in middle-aged men. ${ }^{37}$ The measure also predicts new cardiac events in men and women after successful angioplasty. ${ }^{38}$ The current study expands this knowledge, showing that psychological stress increases the risk of CHD in prehypertensive middle-aged adults.

Strengths of this study include its prospective design and the ARIC study's comprehensive collection of data and outcome surveillance, which allowed for monitoring participants who were free of CVD during multiple visits and follow-up interviews for an extended period to assess development of hypertension and CHD. The cohort had a large proportion of African American patients, a population that is often underrepresented in research studies. Furthermore, the study included assessments of psychosocial factors, such as social support, long-term stress, and anger in addition to traditional risk factors for hypertension. This study provides impetus for further study into treatment of modifiable risk factors that may slow or prevent the progression of prehypertension to hypertension and CHD. Finally, our findings appear robust, as we ran our models numerous ways to ensure proper accounting for confounding and got similar results.

Limitations include the generalizability of the findings to patient populations of different ages. Certain factors may be of differing importance in the progression from prehypertension to hypertension or CHD for younger and older patients. The observational nature of the study limits inference beyond associations. Finally, few women (5.8\%) developed CHD in our cohort, which may account for the lack of association in women. Longer follow-up time may be needed for women with prehypertension.

The Joint National Committee on Prevention, Detection, Evaluation, and Treatment of High Blood Pressure designated prehypertension as a new blood pressure category based on the increased cardiovascular risks and events associated with blood pressures in this range. The findings of this study further support these associations with prehypertenion. Additionally, we were able to show that beyond traditional cardiovascular risk factors, anger and psychological stress play a role in development of CHD in participants with prehypertension. This study serves to further characterize individuals with prehypertension and adds to the growing evidence of the role of psychological factors in the development of cardiovascular disease.

To read or post commentaries in response to this article, see it online at http://www.annfammed.org/cgi/content/full/5/5/403.

Key words: Prehypertension; psychosocial factors; hypertension; anger; stress, psychological

Submitted September 18, 2006; submitted, revised, March 3, 2007; accepted March 25, 2007.

This paper was presented as a distinguished paper at the North American Primary Care Research Group meeting, Tucson, Arizona, October 2006.

Funding support: Supported in part by grants 1D12HP00023 and 1D14HP00161 from the Health Resources and Services Administration.

Acknowledgments: The Atherosclerosis Risk in Communities Study (ARIC) is conducted and supported by the National Heart, Lung, and Blood Institute (NHLBI) in collaboration with the ARIC Study Investigators. This manuscript was prepared using a limited-access data set obtained by the NHLBI and does not necessarily reflect the opinions or views of the ARIC Study or the NHLBI.

\section{References}

1. Fields LE, Burt VL, Cutler JA, Hughes J, Roccella EJ, Sorlie P. The burden of adult hypertension in the United States 1999 to 2000: a rising tide. Hypertension. 2004;44(4):398-404.

2. Stamler J, Stamler R, Neaton JD. Blood pressure, systolic and diastolic, and cardiovascular risks. US population data. Arch Intern Med. 1993;153(5):598-615.

3. Kannel WB. Blood pressure as a cardiovascular risk factor: prevention and treatment. JAMA. 1996;275(20):1571-1576.

4. MacMahon S, Peto R, Cutler J, et al. Blood pressure, stroke, and coronary heart disease. Part 1, Prolonged differences in blood pressure: prospective observational studies corrected for the regression dilution bias. Lancet. 1990;335(8692):765-774.

5. US Department of Health and Human Services. Healthy People 2010: Understanding and Improving Health. 2nd ed. Washington, DC: US Government Printing Office; 2000.

6. American Heart Association. Heart Disease and Stroke Statistics 2005 Update. Dallas, Tex: American Heart Association; 2005.

7. Hurst W. The Heart, Arteries, and Veins. 10th ed. New York, NY: McGraw-Hill; 2002.

8. Vasan RS, Larson MG, Leip EP, et al. Impact of high-normal blood pressure on the risk of cardiovascular disease. N Engl J Med. 2001;345(18):1291-1297.

9. Qureshi Al, Suri MF, Kirmani JF, Divani AA, Mohammad Y. Is prehypertension a risk factor for cardiovascular diseases? Stroke. 2005;36(9):1859-1863.

10. Chobanian AV, Bakris GL, Black HR, et al. The Seventh Report of the Joint National Committee on Prevention, Detection, Evaluation, and Treatment of High Blood Pressure: the JNC 7 report. JAMA. 2003;289(19):2560-2572. 
11. Wang Y, Wang QJ. The prevalence of prehypertension and hypertension among US adults according to the new joint national committee guidelines: new challenges of the old problem. Arch Intern Med. 2004;164(19):2126-2134.

12. Qureshi Al, Suri MF, Kirmani JF, Divani AA. Prevalence and trends of prehypertension and hypertension in United States: National Health and Nutrition Examination Surveys 1976 to 2000. Med Sci Monit. 2005;11(9):CR403-409.

13. Greenlund KJ, Croft JB, Mensah GA. Prevalence of heart disease and stroke risk factors in persons with prehypertension in the United States, 1999-2000. Arch Intern Med. 2004;164(19):2113-2118.

14. Liszka HA, Mainous AG, 3rd, King DE, Everett CJ, Egan BM. Prehypertension and cardiovascular morbidity. Ann Fam Med. 2005;3(4):294-299.

15. Kshirsagar AV, Carpenter M, Bang H, Wyatt SB, Colindres RE. Blood pressure usually considered normal is associated with an elevated risk of cardiovascular disease. Am J Med. 2006;119(2):133-141.

16. Vasan RS, Larson MG, Leip EP, Kannel WB, Levy D. Assessment of frequency of progression to hypertension in non-hypertensive participants in the Framingham Heart Study: a cohort study. Lancet 2001;358(9294):1682-1686.

17. Medalie JH, Goldbourt U. Angina pectoris among 10,000 men. II. Psychosocial and other risk factors as evidenced by a multivariate analysis of a five year incidence study. Am J Med. 1976;60(6):910921.

18. Kawachi I, Sparrow D, Spiro A, 3rd, Vokonas P, Weiss ST. A prospective study of anger and coronary heart disease. The Normative Aging Study. Circulation. 1996;94(9):2090-2095.

19. Kawachi I, Sparrow D, Kubzansky LD, Spiro A, 3rd, Vokonas PS Weiss ST. Prospective study of a self-report type A scale and risk of coronary heart disease: test of the MMPI-2 type A scale. Circulation. 1998;98(5):405-412.

20. Sesso HD, Kawachi I, Vokonas PS, Sparrow D. Depression and the risk of coronary heart disease in the Normative Aging Study. Am J Cardiol. 1998;82(7):851-856.

21. Williams JE, Nieto FJ, Sanford CP, Couper DJ, Tyroler HA. The association between trait anger and incident stroke risk: the Atherosclerosis Risk in Communities (ARIC) Study. Stroke. 2002;33(1):13-19.

22. Eaker ED, Sullivan LM, Kelly-Hayes M, D'Agostino RB, Sr., Benjamin EJ. Anger and hostility predict the development of atrial fibrillation in men in the Framingham Offspring Study. Circulation. 2004;109(10):1267-1271.

23. Jonas BS, Franks P, Ingram DD. Are symptoms of anxiety and depression risk factors for hypertension? Longitudinal evidence from the National Health and Nutrition Examination Survey I Epidemiologic Follow-up Study. Arch Fam Med. 1997;6(1):43-49.
24. Davidson K, Jonas BS, Dixon KE, Markovitz JH. Do depression symptoms predict early hypertension incidence in young adults in the CARDIA study? Coronary Artery Risk Development in Young Adults. Arch Intern Med. 2000;160(10):1495-1500.

25. Yan LL, Liu K, Matthews KA, Daviglus ML, Ferguson TF, Kiefe $\mathrm{Cl}$. Psychosocial factors and risk of hypertension: the Coronary Artery Risk Development in Young Adults (CARDIA) study. JAMA. 2003;290(16):2138-2148.

26. Williams JE, Paton CC, Siegler IC, Eigenbrodt ML, Nieto FJ, Tyroler HA. Anger proneness predicts coronary heart disease risk: prospective analysis from the atherosclerosis risk in communities (ARIC) study. Circulation. 2000;101(17):2034-2039.

27. The Atherosclerosis Risk in Communities (ARIC) Study: design and objectives. The ARIC investigators. Am J Epidemiol. 1989;129(4): 687-702.

28. Clinical Guidelines on the Identification, Evaluation and Treatment of Overweight and Obesity in Adults: The Evidence Report. Bethesda, Md: National Institutes of Health. National Heart, Lung, and Blood Institute in cooperation with the National Institute of Diabetes and Digestive and Kidney Diseases; 1998. NIH publication, No. 98-4083.

29. The Presidents Council on Fitness and Sports, Presidents Challenge. http://www.fitness.gov/home_pres_chall.htm. Accessed: Aug, 22 2006.

30. ExRx.net. Aerobic Exercise Guidelines, Specific Goals. http://www. exrx.net/Aerobic/AerobicGoals.html. Accessed: Aug, 222006.

31. Lubben J. Assessing social networks among elderly populations. Fam Comm Health. 1988;11(3):42-52.

32. Appels A, Hoppener P, Mulder P. A questionnaire to assess premonitory symptoms of myocardial infarction. Int J Cardiol. 1987;17(1):15-24.

33. Spielberger C, Jacobs G, Russel S, Crane R. Assessment of anger: the State-Trait Anger Scale. In: Butcher J, Spielberger C, eds. Advances in Personality Assessment. Hillsdale, NJ: Lawrence Erlbaum Associates; 1983:161-189.

34. Julius S. Corcoran Lecture. Sympathetic hyperactivity and coronary risk in hypertension. Hypertension. 1993;21(6 Pt 2):886-893.

35. Palatini P. Sympathetic overactivity in hypertension: a risk factor for cardiovascular disease. Curr Hypertens Rep. 2001;3(Suppl 1):S3-S9.

36. Blumenthal JA, Williams RS, Williams RB, Jr., Wallace AG. Effects of exercise on the Type A (coronary prone) behavior pattern. Psychosom Med. 1980;42(2):289-296.

37. Appels A, Mulder P. Excess fatigue as a precursor of myocardial infarction. Eur Heart J. 1988;9(7):758-764.

38. Kop WJ, Appels AP, Mendes de Leon CF, de Swart HB, Bar FW. Vital exhaustion predicts new cardiac events after successful coronary angioplasty. Psychosom Med. 1994;56(4):281-287. 